\title{
The impact of marginal lung function on outcomes in the era of minimally invasive thoracic surgery
}

\author{
Hiroko Nakahama, Mark Jaradeh, Zaid M. Abdelsattar, James Lubawski, Wickii T. Vigneswaran \\ Department of Thoracic and Cardiovascular Surgery, Loyola University Medical Center, Maywood, IL, USA \\ Contributions: (I) Conception and design: All authors; (II) Administrative support: ZM Abdelsattar, J Lubawski, WT Vigneswaran; (III) Provision \\ of study materials or patients: All authors; (IV) Collection and assembly of data: H Nakahama, M Jaradeh; (V) Data analysis and interpretation: \\ H Nakahama, ZM Abdelsattar, WT Vigneswaran; (VI) Manuscript writing: All authors; (VII) Final approval of manuscript: All authors. \\ Correspondence to: Wickii T. Vigneswaran, MD, MBA, FACS. Department of Cardiothoracic Surgery, Loyola University Medical Center, Maywood, \\ IL 60153, USA. Email: wickii.vigneswaran@lumc.edu.
}

Background: The effect of marginal lung function on outcomes after lung resection has traditionally been studied in the context of open thoracic surgery. Its impact on postoperative outcomes in the era of minimally invasive lung resection is unclear.

Methods: In this retrospective cohort study, we included adult patients who underwent minimally invasive lung resection at our institution between January 2017 and May 2020 for known malignancy or lung nodule. Marginal lung function was defined as pre-operative forced expiratory volume in 1 second (FEV1) and/or diffusion lung capacity of carbon monoxide $<60 \%$ of predicted. Our outcomes included a composite outcome of pulmonary morbidity and/or 30- and 90-day mortality, and hospital length of stay. We used multivariable logistic and Poisson regression models to identify associations with outcomes, and Kaplan-Meier and Cox models to estimate survival.

Results: Of 300 patients, 88 (29\%) had marginal lung function. Patients in the marginal group were more likely to be female ( $69 \%$ vs. $56 \%$; $\mathrm{P}=0.028)$, and more likely to have: hypertension (HTN) ( $83 \%$ vs. $71 \% ; \mathrm{P}=0.028)$, chronic obstructive pulmonary disease (COPD) $(38 \%$ vs. $12 \% ; \mathrm{P}<0.001)$, interstitial lung disease (ILD) ( $9 \%$ vs. $3 \% ; \mathrm{P}<0.019)$, and ischemic heart disease $(28 \%$ vs. $18 \% ; \mathrm{P}=0.033)$. Patients were similar in terms of age $(68 \pm 8$ vs. $68 \pm 10$ years; $\mathrm{P}=0.932)$, and other comorbidities. Anatomic lung resection comprised $56.8 \%$ of the marginal group $v s .74 \%$ in the non-marginal group $(\mathrm{P}=0.003)$. The most common complication was prolonged air leak (18.2\% vs. $11.8 \%$; $\mathrm{P}=0.479)$. Marginal lung function had a trend toward increased composite respiratory complications $(22.7 \%$ vs. $15.1 \% ; \mathrm{P}=0.112)$ and 90 -day mortality $(5.7 \%$ vs. $4.2 \% ; \mathrm{P}=0.591)$, although they did not reach statistical significance. There was a statistically significant 1-day average increase in length of stay in the marginal lung function cohort $(4.6$ vs. 3.4 days; $\mathrm{P}<0.015)$ with a stronger association with diffusion lung capacity of carbon monoxide than FEV1. Survival was similar (marginal function $\mathrm{HR}=1.0 ; \mathrm{P}=0.994$ ).

Conclusions: In the era of minimally invasive thoracic surgery, lung resection in patients with marginal lung function may be considered in select patients. These findings aid in the selection consideration and counseling of this patient population.

Keywords: Minimally invasive thoracic surgery; marginal lung function; robotic-assisted thoracic surgery (RATS)

Submitted Aug 21, 2021. Accepted for publication Oct 28, 2021.

doi: $10.21037 /$ jtd-21-1382

View this article at: https://dx.doi.org/10.21037/jtd-21-1382 


\section{Introduction}

Pre-operative pulmonary lung function tests have long been utilized to predict post-operative outcomes following lung resection. Specifically, low percent predicted values for forced expiratory volume in 1 second (FEV1) and diffusion lung capacity of carbon monoxide (DLCO) have been shown to be associated with increased morbidity and mortality (1-4). Thus, some patients with marginal lung function are traditionally viewed as high risk operative candidates and often get referred to alternative non-surgical methods of treatment such as stereotactic body radiation therapy (SBRT) or radiofrequency ablation (RFA) (5-11). It is important to note that the impact of marginal lung function is based mainly on studies on patients undergoing open thoracotomy and lung resection.

However, with the advent of minimally invasive surgery, many studies have compared the minimally invasive approach [e.g., video-assisted thoracic surgery (VATS) or robotic-assisted thoracic surgery (RATS)] to open thoracotomy, and demonstrated lower perioperative complications overall (12-22). Since current guidelines are based on studies of patients who underwent thoracotomy, the impact of marginal lung function on patients undergoing VATS or RATS lung resection is unclear. Granular data on outcomes following minimally invasive lung resection in patients with marginal lung function are limited.

In this context, we studied the impact of marginal lung function on patients undergoing minimally invasive surgery at a single tertiary center where nearly all lung resections are performed in a minimally invasive fashion. Specifically, we analyzed morbidity, length of stay, perioperative mortality and long-term survival relative to marginal lung function. The findings can help with shared decision making in this patient population in the era of minimally invasive thoracic surgery.

We present the following article in accordance with the STROBE reporting checklist (available at https://dx.doi. org/10.21037/jtd-21-1382).

\section{Methods}

\section{Patient population}

The study was conducted in accordance with the Declaration of Helsinki (as revised in 2013). The study was approved by institutional review board of Loyola University Medical Center (No. 211663: the registration number of ethics board) and individual consent for this retrospective analysis was waived. We used our institutional database to identify all patients who underwent pulmonary resection via VATS or RATS between January 2017 to May 2020. We included all adult patients (age $>18$ years old) who underwent lobectomy, segmentectomy or wedge resection for known or suspected malignancy. We did not include patients undergoing open surgery, those who underwent pneumonectomy, or those who underwent a wedge lung biopsy.

\section{Independent variables}

Preoperative clinical and demographic characteristics included age at presentation, gender, and pre-existing comorbid conditions including: hypertension (HTN), coronary artery disease (CAD), diabetes mellitus (DM), cerebral vascular disease, pulmonary hypertension (pHTN), smoking history, chronic obstructive pulmonary disease (COPD), co-existing cancer, venous thromboembolism (VTE), interstitial lung disease (ILD), myocardial infarction (MI), peripheral vascular disease (PVD), congestive heart failure (CHF), liver dysfunction, atrial fibrillation (afib), and Zubrod score. Zubrod score was defined as 0 for asymptomatic patients, 1 for symptomatic but completely ambulatory patients, 2 for symptomatic but $<50 \%$ in bed during the day, 3 for symptomatic and in bed $>50 \%$ of the time but not bedbound, and 4 for bedbound patients. Tumor pathology including tumor size, location, clinical TNM stage, and tissue histology were collected. Lung resection was defined as either anatomic (segmentectomy or lobectomy) or non-anatomic (wedge resection). Surgical resection was performed by two surgeons and the technique for VATS and RATS was consistent throughout the study. VATS was performed with 4 ports for anatomic resections and 3 ports for wedge resections. RATS was performed using 4 robotic ports or a 5 th port for a robotic stapler for anatomic resections and 4 robotic ports for wedge resections. Missing data in categoric variables were modeled as a separate "unknown" category.

\section{Exposure variables and outcomes}

The main exposure variable was marginal lung function $v s$. normal lung function. Marginal lung function was defined as preoperative FEV1 and/or DLCO $<60 \%(1,2)$. The primary outcomes were the occurrence of composite pulmonary complication within 30 days and/or 30- and 90-day mortality as a composite variable. Pulmonary 
complications were defined as prolonged air leak $>5$ days, pneumonia, acute pulmonary embolism, pneumothorax requiring chest tube replacement, and ventilator dependence for $>48 \mathrm{~h}$. Intervention for prolonged air leak was defined as mechanical or chemical pleurodesis, endobronchial valve placement, or operative resection. Our secondary outcomes included hospital length of stay measured in days. Lastly, overall survival data was collected from the date of last follow-up and/or phone calls to each individual patient if the last follow-up date was not in the past year.

\section{Statistical analysis}

Clinical and demographic variables for patients with preoperative marginal or normal lung function were analyzed using $\chi^{2}$ tests for categorical variables and Student $t$-tests for continuous variables, as indicated.

Independent variables with $\mathrm{P}$ values $<0.200$ were then entered into a multivariable logistic regression model predicting the binary composite outcome of morbidity and mortality. From this model, the beta-coefficients were used to calculate the predicted probability of the composite at deciles of each lung function metric. All other variables were held as observed. A separate Poisson regression model was used to predict hospital length of stay in days and identify associations with outcomes. Poisson models were used given the skewed distribution. Similar to the previous model, the beta coefficients were used to calculate the predicted length of stay in days per decile of pulmonary function metric, while holding all other variables as observed. This methodology allows for identifying the specific contribution of the pulmonary function values while adjusting for other important variables.

Finally, Kaplan-Meier survival analyses were then performed and differences assessed using the log-rank test. All tests were two-sided, with significance set at a $\mathrm{P}$ value of less than 0.05 . The statistical analyses were conducted using Stata 13.1 software (StataCorp., College Station, TX, USA).

\section{Results}

Of 300 patients who underwent minimally invasive thoracic surgery, 88 (29\%) had marginal lung function. Patients in the marginal lung function group were more likely to be female $(69 \%$ vs. $56 \% ; \mathrm{P}=0.028)$, and more likely to have: COPD $(38 \%$ vs. $12 \% ; \mathrm{P}<0.001)$ and ILD (9\% vs. $3 \%$;
$\mathrm{P}<0.019)$. In these patients, the incidence of ischemic heart disease $(28 \%$ vs. $18 \% ; \mathrm{P}=0.033)$ and $\mathrm{HTN}(83 \%$ vs. $71 \%$; $\mathrm{P}=0.028)$ were also higher. Patients were similar in terms of their age $(68 \pm 8$ vs. $68 \pm 10$ years; $\mathrm{P}=0.932)$, and their other comorbidities, as shown in Table 1. Anatomic lung resection was less commonly performed in the marginal lung function group, but still comprised $56.8 \%$ of lung resections, compared to $74.1 \%$ in the non-marginal group $(\mathrm{P}=0.003)$. Of the patients that underwent anatomic lung resections, the use of segmentectomy was significantly higher in the marginal lung function group compared to normal lung function $(13.6 \%$ vs. 9.4\%; $\mathrm{P}=0.003)$ (Table 1$)$.

The pre-operative FEV1 in patients with marginal lung function ranged from $28-59 \%$ with a median of $50 \%$, and pre-operative DLCO ranged from $18-59 \%$ with a median of $54 \%$. In contrast, pre-operative FEV1 and DLCO of normal lung function ranged from $60-137 \%$ with a median of $86 \%$ for FEV1 and $82 \%$ for DLCO (Table 1).

The most common complication in the marginal lung function cohort was prolonged air leak $(18.2 \%$ vs. $11.8 \%$; $\mathrm{P}=0.142$ ), as shown in Table 2. The majority of patients that had prolonged air leak underwent conservative management with continuation of a chest tube; $1 / 16(6.3 \%)$ of marginal lung function patients with an air leak underwent intervention with chemical pleurodesis and 2/25 (8.0\%) patients with normal lung function underwent intervention $(\mathrm{P}>0.999)$, one patient with chemical pleurodesis and one patient with endobronchial valve placement. Overall, marginal lung function was associated with a trend toward increased composite respiratory complications $(22.7 \%$ vs. $15.1 \% ; \mathrm{P}=0.112$ ) (Figure 1), 90-day mortality (5.7\% vs. $4.2 \% ; \mathrm{P}=0.591)$, and the composite outcome of respiratory morbidity and/or 90 -day mortality $(27.2 \%$ vs. $17.9 \%$; $\mathrm{P}=0.069$ ), although none of these outcomes reached statistical significance, as shown in Table 3.

However, there was a 1-day average increase in length of stay in the marginal lung function cohort (4.6 vs. 3.4 days; $\mathrm{P}<0.015)$. On multivariable analysis, this increased length of stay association is noted across deciles of FEV1 and DLCO (Figure 1), with a stronger association with DLCO than FEV1. There was an increasing trend toward an association between individual lung function metrics with the composite respiratory outcome, although this did not reach statistical significance.

Lastly, median follow-up was 699 days. On Kaplan-Meier analysis, long term overall survival was similar between the two cohorts, as shown in Figure $2(\mathrm{P}=0.994)$. 
Table 1 Baseline characteristics and types of surgical resection between patients with marginal lung function and normal lung function

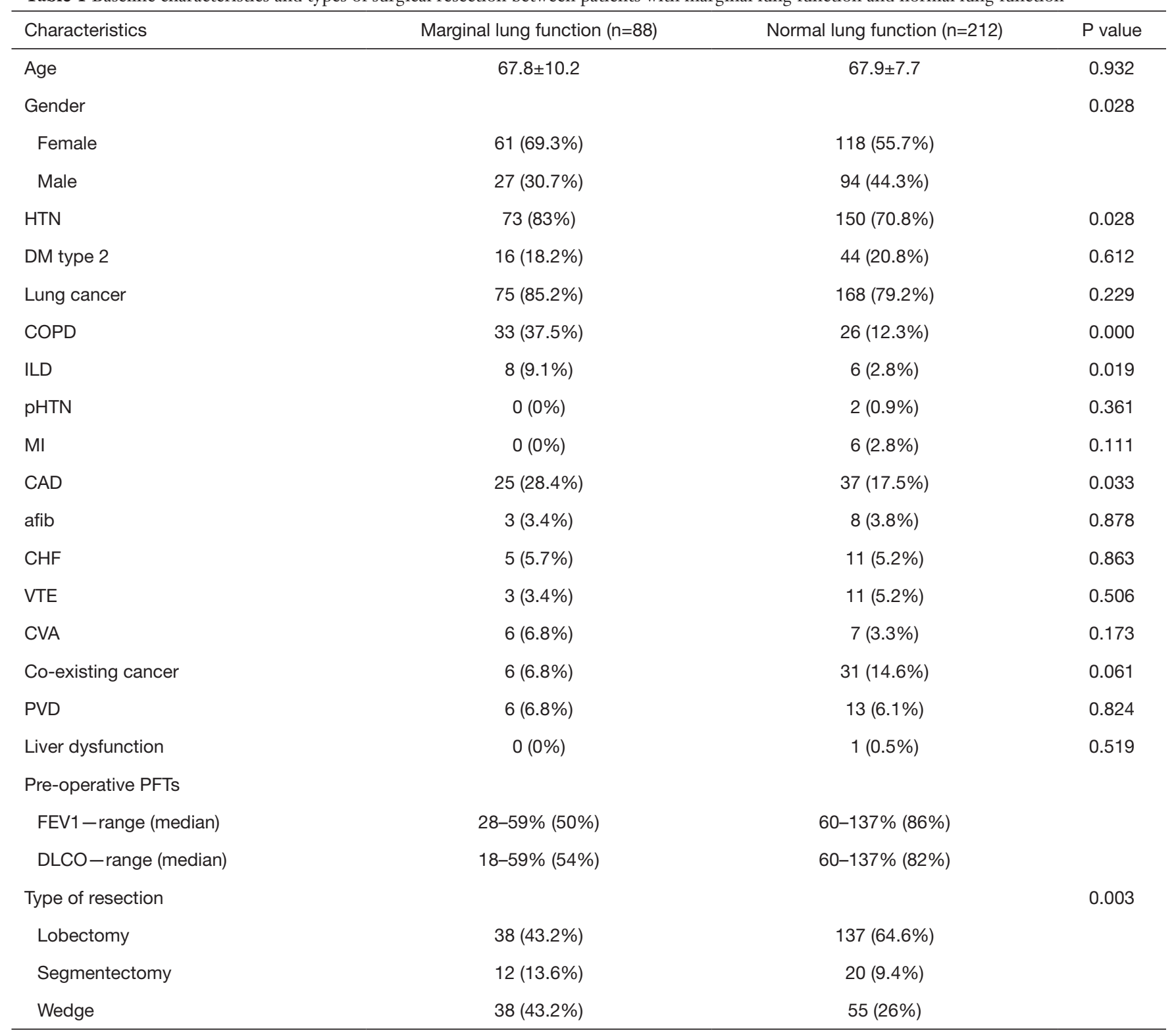

HTN, hypertension; DM, diabetes mellitus; COPD, chronic obstructive pulmonary disease; ILD, interstitial lung disease; pHTN, pulmonary hypertension; MI, myocardial infarction; CAD, coronary artery disease; afib, atrial fibrillation; CHF, congestive heart failure; VTE, venous thromboembolism; CVA, cerebral vascular accident; PVD, peripheral vascular disease; PFTs, pulmonary function tests; FEV1, forced expiratory volume in 1 second; DLCO, diffusion lung capacity of carbon monoxide.

\section{Discussion}

In this contemporary, single-institution observational study of 300 patients who underwent minimally invasive lung resection for lung cancer or pulmonary nodules, we found that: (I) nearly 1 in 3 of our patients had marginal lung function and half of those underwent anatomic lung resection; (II) there was a trend toward increased morbidity and 90-day mortality in marginal lung function group although this did not reach statistical significance; and (III) there was a 1-day on average increased length of stay in patients with marginal lung function.

With the advent of minimally invasive surgery, patients with marginal lung function are increasingly undergoing surgical resection for lung cancer. Previous guidelines by 
Table 2 Thirty-day respiratory complications

\begin{tabular}{|c|c|c|c|}
\hline Thirty-day respiratory complications & Marginal lung function $(n=88)$ & Normal lung function $(n=212)$ & $P$ value \\
\hline Intervention for prolonged air leak & $1 / 16(6.3 \%)$ & $2 / 25(8.0 \%)$ & 0.999 \\
\hline Pneumothorax & $4(10.5 \%)$ & $9(12.7 \%)$ & 0.741 \\
\hline Pneumonia & $2(5.3 \%)$ & $5(7 \%)$ & 0.718 \\
\hline Tracheostomy & $0(0 \%)$ & $2(2.8 \%)$ & 0.296 \\
\hline Pulmonary embolus & $1(2.6 \%)$ & $1(1.4 \%)$ & 0.955 \\
\hline Ventilator support $>48 \mathrm{~h}$ & $0(0 \%)$ & $1(1.4 \%)$ & 0.462 \\
\hline Respiratory failure & $2(5.3 \%)$ & $1(1.4 \%)$ & 0.241 \\
\hline
\end{tabular}
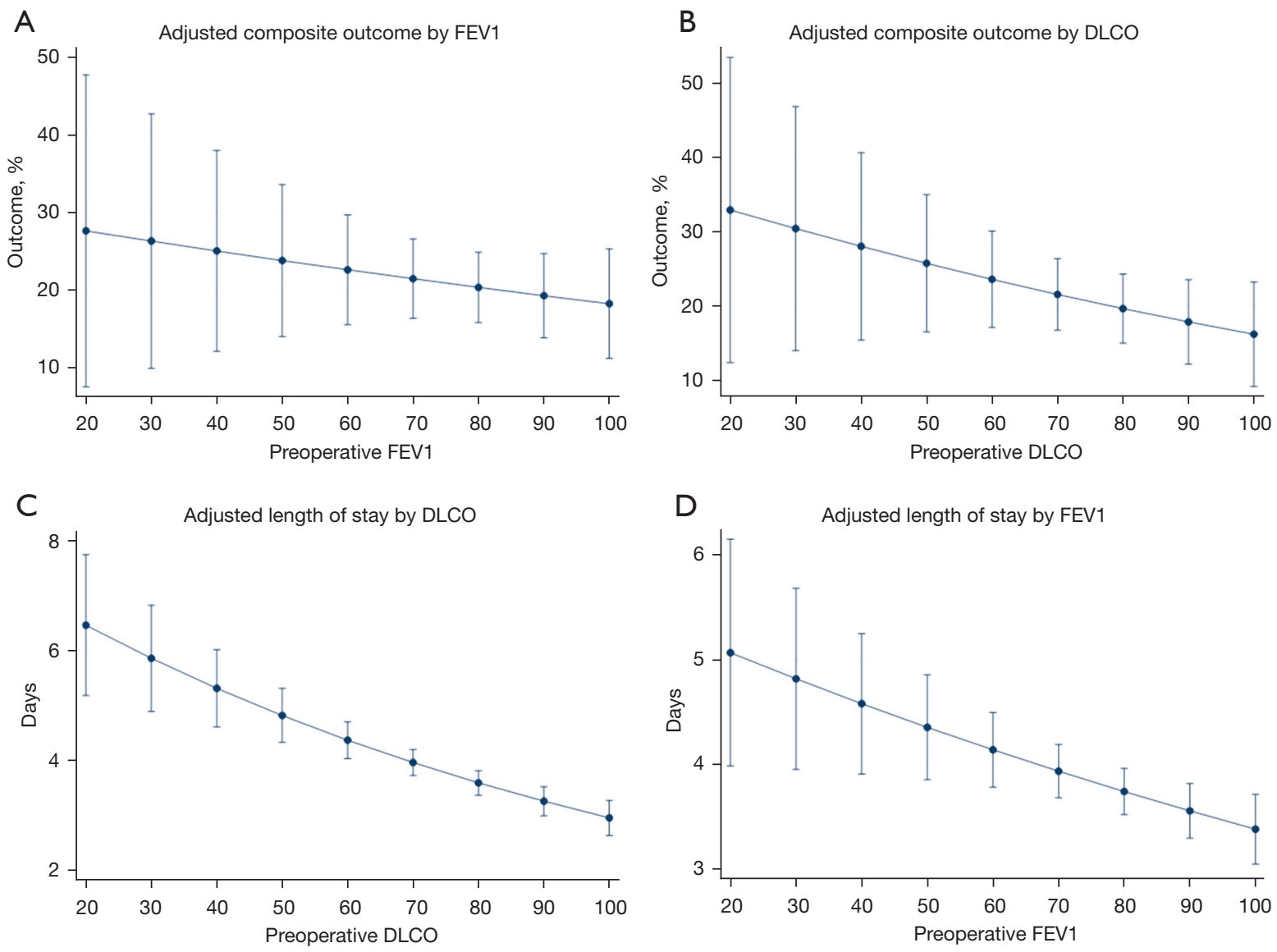

Figure 1 Adjusted composite outcome and length of stay by FEV1 and DLCO. (A) Ninety-day composite respiratory outcome by deciles of FEV1. (B) Ninety-day composite respiratory outcome by deciles of DLCO. (C) Adjusted length of stay by deciles of DLCO. (D) Adjusted length of stay by deciles of FEV1. Note that FEV1 and DLCO are not significantly associated with the composite outcome, but are associated with length of stay. DLCO has a stronger association than FEV1. FEV1, forced expiratory volume in 1 second; DLCO, diffusion lung capacity of carbon monoxide. 
Table 3 Thirty- and 90-day mortality, composite respiratory outcomes, and composite respiratory and 90-day mortality

\begin{tabular}{lccc}
\hline Composite outcomes & Marginal lung function & Normal lung function & P value \\
\hline Thirty-day mortality & $1(0.9 \%)$ & $3(1.1 \%)$ & 0.878 \\
Ninety-day mortality & $5(5.7 \%)$ & $9(4.2 \%)$ & 0.591 \\
Respiratory complications & $20(22.7 \%)$ & $32(15.1 \%)$ & 0.112 \\
Composite respiratory and 90-day mortality & $24(27.2 \%)$ & $38(17.9 \%)$ & 0.069 \\
\hline
\end{tabular}

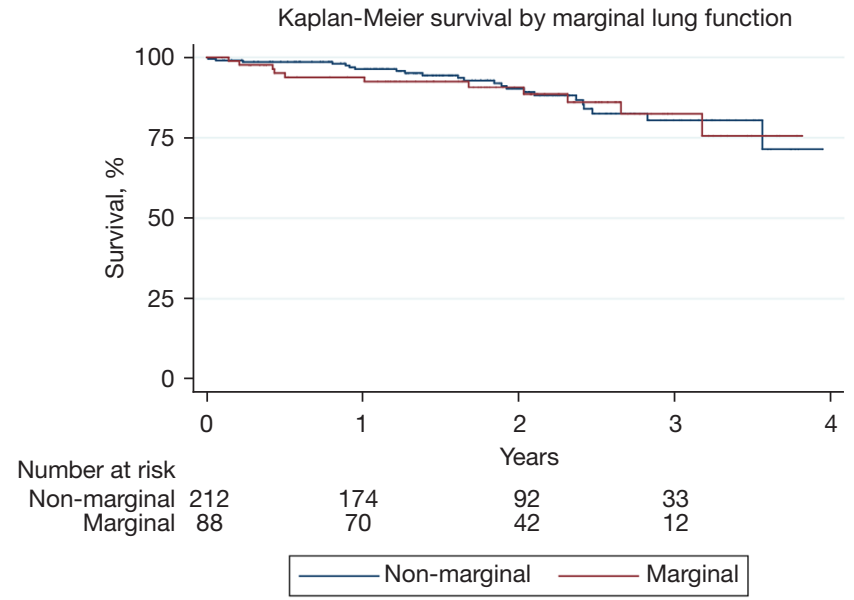

Figure 2 No significant difference in overall survival on KaplanMeier curve.

American College of Chest Physicians (ACCP), European Respiratory Society (ERS)/European Society of Thoracic Surgeons (ESTS), and British Thoracic Society (BTS) emphasized limitations of surgical resection in patients that were deemed high risk for surgery based on pulmonary function tests (PFTs) and patient co-morbidities (1-3). Patients deemed too high risk for surgical resection with early stage I lung cancer are referred for stereotactic body radiation therapy (SBRT) or radiofrequency ablation (RFA) based on American Society for Radiation Oncology (ASRO) guidelines (5). SBRT has been successful in local control with recurrence rates reported as low as $10 \%$ in short-term follow-up (6-9). Short-comings of SBRT include difficulty in surveilling tumors via imaging due to radiation-induced lung injury and omission of invasive lymph node staging prior to treatment, causing reportedly higher distant recurrence rates (9). RFA has been reported to have high recurrence rate and may be limited in efficacy in larger tumor sizes $>3 \mathrm{~cm}(10,11)$. A 2015 analysis of the Surveillance, Epidemiology, and End Results (SEER) database comparing SBRT to surgical resection for stage I non-small cell lung cancer found a lower 90-day mortality rate in the SBRT group compared to surgery (2.2\% vs. $6.1 \%$; $\mathrm{P}=0.005$ ); however, this outcome was reversed by 1 year, with a significantly higher mortality for SBRT compared to surgery $(40.1 \%$ vs. $22.3 \%$; $\mathrm{P}<0.001)(12)$. To stratify out any underlying co-morbid conditions that are inherently higher in patients selected for SBRT, a large National Cancer Database analysis comparing propensity-matched SBRT to lobectomy for operable stage I lung cancer found a significant difference in 5-year overall survival (29\% SBRT vs. $59 \%$ lobectomy; $\mathrm{P}<0.001)(13)$. Due to limitations in non-surgical approaches as well as data suggesting higher overall survival in the surgical cohort in long-term follow-up, expanding criteria for surgical resection in poor lung function candidates should be considered, particularly in patients with longer life expectancy.

Updated guidelines by ACCP in 2013 includes grade 1c evidence for consideration of minimally invasive surgery in patients deemed surgically high risk (14). Indeed, our overall composite respiratory complications and 30-day mortality were similar to previous studies (15-22). Our 90-day mortality of $5.7 \%$ and $4.2 \%$ for marginal lung and normal lung function, respectively, are similar to 90-day mortality of $6.1 \%$ following lung resection from the SEER database (12). The 90-day mortality is not frequently reported in literature but we included it in our study to report the trend. Berry et al. (17) demonstrated that marginal lung function patients had significantly lower respiratory complications and mortality when undergoing thoracoscopic surgery compared to thoracotomy. Reported 30-day mortality for marginal lung function patients who underwent VATS ranged from $1-3 \%$ and similar to our reported 30 -day mortality of $1 \%(17,20)$. Similar associations were made when comparing RATS to open approach for marginal lung function patients (20-22). These results are postulated to be related to decreased post-operative pain from elimination of rib spreading and preserving chest wall anatomy as well as reduced manipulation of lung parenchyma $(17,22-25)$. 
Our study was unique in that we compared marginal lung function patients to normal lung function patients who had all undergone minimally invasive surgery. Although there was no significant difference demonstrated in composite respiratory outcome and mortality, however, the groups in this study were not powered to detect this difference. Future studies with a larger patient population or a multicenter study may help elucidate these differences. Our data is a contemporary study that used the most recent data available at our institution, thus we had limited long-term follow-up data for the more recent surgical patients. Notwithstanding this limitation, the increasing trend in composite respiratory outcome was not associated with overall survival on the Kaplan-Meier analysis.

Although our marginal lung function cohort had a significantly lower rate of anatomic lung resection, this was not associated with increased mortality in these patients after 90 -day or decreased overall survival. Lobectomy is currently the gold standard therapy for resectable lung cancer based on a landmark randomized control trial by the Lung Cancer Study Group in 1995 (26). Old paradigms have been challenged by recent advancements in preoperative imaging, staging modalities, and minimally invasive surgery (27). There has been an increase in anatomic segmentectomies in patients undergoing minimally invasive surgery for early lung cancer, likely related to worse pulmonary function in this patient cohort; however, no associated difference in overall morbidity or mortality have been observed $(20-25,28)$. The recently reported JCOG0802/ WJOG4607L phase III randomized control trial compared segmentectomy and lobectomy for stage Ia peripheral nonsmall cell lung cancer $\leq 2 \mathrm{~cm}$ in diameter (29). They found a significant difference in post-operative air leak in patients who underwent segmentectomy compared to lobectomy; this difference was attributed to increased technical surgical complexity of segmentectomy compared to lobectomy although these findings did not result in any differences in morbidity or mortality (29). It is possible that the increased air leak in the marginal lung function group in our study may be due to higher incidence of segmentectomy among these patients. Furthermore, updated data presented at the American Association for Thoracic Surgery 101st annual meeting demonstrated superiority in 5-year overall survival of segmentectomy compared to lobectomy $(94.3 \% v s$. 91.1\%; $\mathrm{P}=0.0082$ ), albeit a higher loco-regional recurrence (12.1\% vs. $7.9 \% ; \mathrm{P}=0.0214$ ) (30). Compared to lobectomies, segmentectomies preserve more lung parenchyma and subsequently pulmonary physiology, thus contributing to the improved perioperative respiratory outcome (27-29). Nonanatomical resection, especially in early stage cancer, related to composite outcomes warrant further investigation. In addition, there have been limited studies assessing the appropriate "cutoff" value in FEV1 or DLCO for minimally invasive lung resection and the appropriate surgical procedure for each marginal or "high risk" patient based on pre-operative lung function values. Larger studies to power for each range of FEV1 and DLCO can help delineate these differences.

In this study, marginal lung function was associated with increased hospital length of stay although the overall length of stay is short in both groups. Reported median length of stay of patients undergoing minimally invasive surgery for lung resection ranged from 2 to 5 days although these studies did not stratify length of stay based on lung function $(17,20,25,28)$. In our patient population, marginal lung function patients had significantly elevated co-morbid conditions that could contribute to this finding, although the length of stay is similar to reported median length of stay in similar studies. Furthermore, the longer length of stay had a stronger association with patients with DLCO $<60 \%$ compared to FEV $1<60 \%$ or normal lung function. Consistent with our findings, there have been multiple reports demonstrating DLCO as an independent risk factor for patients undergoing lung resection (31-34). The stepwise increase in length of stay for every 10 percentage points decrease demonstrates the strength of this association. The absence of such a relationship with overall survival on the other hand, suggests that in the minimally invasive approach to lung resection, those effects are largely blunted.

Our findings in this study indicate that surgical resection with a minimally invasive approach should be considered in patients with marginal lung function. However, it's important to emphasize the importance of surgeon judgement and patient selection in this patient population. Although PFTs are helpful adjuncts in predicting outcome after lung resection, patient co-morbid conditions, social factors, and type of surgical resection need to be considered prior to offering surgery. Important discussions regarding outcome of surgical intervention are respiratory complications, especially prolonged air leak that potentially require intervention, and increased hospitalization days should be included in the shared decision-making with patients.

This study has several limitations. First, this is an observational study subject to inherent selection bias and 
confounding. We included all consecutive lung resection patients at our institution to mitigate this; however, we do not have data on patients with marginal lung function who were deemed poor operative candidates. Although this is a major limitation, it does highlight the importance of the surgeon's judgment at the preoperative visit. Second, the type of surgical resection that was performed, namely lobectomy, segmentectomy, or wedge resection, were determined by surgeon judgement based on patient baseline parameters and preoperative lung function. More objective guidelines for determining the surgical approach based on patient lung function is a target for further studies. Finally, these surgical results are from a single center and the sample size was small, thus, the results might not be generalizable. The small sample limited the ability to propensity match between the marginal lung function and normal lung function group to assess composite outcome and survival. Although propensity match was not performed due to small sample size, a logistic regression model was used to adjust for important confounders. Notwithstanding these limitations, we believe the findings are contemporary, relevant, and reflect modern thoracic surgical practice. The finding of increased length of stay in patient with marginal lung function help in patient counseling and can identify targets for quality improvement.

In conclusion, select patients with marginal lung function can safely undergo lung resection utilizing minimally invasive approaches albeit an increased trend in composite respiratory outcome and 90-day mortality. Larger studies are warranted to statistically power for any significant associations. Hospital length of stay is short overall, but those with marginal lung function should be expected to stay 1 day longer on average. In summary, this information should be considered in shared decision-making with the patients and multi-disciplinary team.

\section{Acknowledgments}

Funding: None.

\section{Footnote}

Reporting Checklist: The authors have completed the STROBE reporting checklist. Available at https://dx.doi. org/10.21037/jtd-21-1382

Data Sharing Statement: Available at https://dx.doi. org/10.21037/jtd-21-1382
Peer Review File: Available at https://dx.doi.org/10.21037/ jtd-21-1382

Conflicts of Interest: All authors have completed the ICMJE uniform disclosure form (available at https://dx.doi. org/10.21037/jtd-21-1382). The authors have no conflicts of interest to declare.

Ethical Statement: The authors are accountable for all aspects of the work in ensuring that questions related to the accuracy or integrity of any part of the work are appropriately investigated and resolved. The study was conducted in accordance with the Declaration of Helsinki (as revised in 2013). The study was approved by institutional review board of Loyola University Medical Center (No. 211663: the registration number of ethics board) and individual consent for this retrospective analysis was waived.

Open Access Statement: This is an Open Access article distributed in accordance with the Creative Commons Attribution-NonCommercial-NoDerivs 4.0 International License (CC BY-NC-ND 4.0), which permits the noncommercial replication and distribution of the article with the strict proviso that no changes or edits are made and the original work is properly cited (including links to both the formal publication through the relevant DOI and the license). See: https://creativecommons.org/licenses/by-nc-nd/4.0/.

\section{References}

1. Brunelli A, Charloux A, Bolliger CT, et al. ERS/ESTS clinical guidelines on fitness for radical therapy in lung cancer patients (surgery and chemo-radiotherapy). Eur Respir J 2009;34:17-41.

2. British Thoracic Society; Society of Cardiothoracic Surgeons of Great Britain and Ireland Working Party. BTS guidelines: guidelines on the selection of patients with lung cancer for surgery. Thorax 2001;56:89-108.

3. Lim E, Baldwin D, Beckles M, et al. Guidelines on the radical management of patients with lung cancer. Thorax 2010;65 Suppl 3:iii1-27.

4. López-Encuentra A, Pozo-Rodríguez F, Martín-Escribano $\mathrm{P}$, et al. Surgical lung cancer. Risk operative analysis. Lung Cancer 2004;44:327-37.

5. Schneider BJ, Daly ME, Kennedy EB, et al. Stereotactic Body Radiotherapy for Early-Stage Non-Small-Cell Lung Cancer: American Society of Clinical Oncology Endorsement of the American Society for Radiation 
Oncology Evidence-Based Guideline. J Clin Oncol 2018;36:710-9.

6. Fakiris AJ, McGarry RC, Yiannoutsos CT, et al. Stereotactic body radiation therapy for early-stage non-small-cell lung carcinoma: four-year results of a prospective phase II study. Int J Radiat Oncol Biol Phys 2009;75:677-82.

7. Baumann P, Nyman J, Hoyer M, et al. Outcome in a prospective phase II trial of medically inoperable stage I non-small-cell lung cancer patients treated with stereotactic body radiotherapy. J Clin Oncol 2009;27:3290-6.

8. Nagata Y, Hiraoka M, Shibata T, et al. Prospective Trial of Stereotactic Body Radiation Therapy for Both Operable and Inoperable T1N0M0 Non-Small Cell Lung Cancer: Japan Clinical Oncology Group Study JCOG0403. Int J Radiat Oncol Biol Phys 2015;93:989-96.

9. Sun B, Brooks ED, Komaki RU, et al. 7-year follow-up after stereotactic ablative radiotherapy for patients with stage I non-small cell lung cancer: Results of a phase 2 clinical trial. Cancer 2017;123:3031-9.

10. Pennathur A, Luketich JD, Abbas G, et al. Radiofrequency ablation for the treatment of stage I non-small cell lung cancer in high-risk patients. J Thorac Cardiovasc Surg 2007;134:857-64.

11. Lanuti M, Sharma A, Willers H, et al. Radiofrequency ablation for stage I non-small cell lung cancer: management of locoregional recurrence. Ann Thorac Surg 2012;93:921-7; discussion 927-88.

12. Yu JB, Soulos PR, Cramer LD, et al. Comparative effectiveness of surgery and radiosurgery for stage I nonsmall cell lung cancer. Cancer 2015;121:2341-9.

13. Rosen JE, Salazar MC, Wang Z, et al. Lobectomy versus stereotactic body radiotherapy in healthy patients with stage I lung cancer. J Thorac Cardiovasc Surg 2016;152:44-54.e9.

14. Brunelli A, Kim AW, Berger KI, et al. Physiologic evaluation of the patient with lung cancer being considered for resectional surgery: Diagnosis and management of lung cancer, 3rd ed: American College of Chest Physicians evidence-based clinical practice guidelines. Chest 2013;143:e166S-90S.

15. Alam NZ. Lung resection in patients with marginal pulmonary function. Thorac Surg Clin 2014;24:361-9.

16. Ceppa DP, Kosinski AS, Berry MF, et al. Thoracoscopic lobectomy has increasing benefit in patients with poor pulmonary function: a Society of Thoracic Surgeons Database analysis. Ann Surg 2012;256:487-93.
17. Berry MF, Villamizar-Ortiz NR, Tong BC, et al. Pulmonary function tests do not predict pulmonary complications after thoracoscopic lobectomy. Ann Thorac Surg 2010;89:1044-51; discussion 1051-2.

18. Villamizar NR, Darrabie MD, Burfeind WR, et al. Thoracoscopic lobectomy is associated with lower morbidity compared with thoracotomy. J Thorac Cardiovasc Surg 2009;138:419-25.

19. Paul S, Altorki NK, Sheng S, et al. Thoracoscopic lobectomy is associated with lower morbidity than open lobectomy: a propensity-matched analysis from the STS database. J Thorac Cardiovasc Surg 2010;139:366-78.

20. Kneuertz PJ, D’Souza DM, Moffatt-Bruce SD, et al. Robotic lobectomy has the greatest benefit in patients with marginal pulmonary function. J Cardiothorac Surg 2018;13:56.

21. Casiraghi M, Spaggiari L. Robotic lobectomy has the greatest benefit in patients with marginal pulmonary function. J Thorac Dis 2019;11:S322-4. Erratum in: J Thorac Dis 2019;11:E151.

22. Veronesi G, Bruschini P, Novellis P. Robotic surgery can extend surgical indication in patients with lung cancer and impaired function. J Thorac Dis 2019;11:E224-8.

23. Emmert A, Straube C, Buentzel J, et al. Robotic versus thoracoscopic lung resection: A systematic review and meta-analysis. Medicine (Baltimore) 2017;96:e7633.

24. Mungo B, Hooker CM, Ho JS, et al. Robotic Versus Thoracoscopic Resection for Lung Cancer: Early Results of a New Robotic Program. J Laparoendosc Adv Surg Tech A 2016;26:243-8.

25. Pardolesi A, Park B, Petrella F, et al. Robotic anatomic segmentectomy of the lung: technical aspects and initial results. Ann Thorac Surg 2012;94:929-34.

26. Ginsberg RJ, Rubinstein LV. Randomized trial of lobectomy versus limited resection for T1 N0 non-small cell lung cancer. Lung Cancer Study Group. Ann Thorac Surg 1995;60:615-22; discussion 622-3.

27. Yang CF, D'Amico TA. Open, thoracoscopic and robotic segmentectomy for lung cancer. Ann Cardiothorac Surg 2014;3:142-52.

28. Huang L, Shen Y, Onaitis M. Comparative study of anatomic lung resection by robotic vs. video-assisted thoracoscopic surgery. J Thorac Dis 2019;11:1243-50.

29. Suzuki K, Saji H, Aokage K, et al. Comparison of pulmonary segmentectomy and lobectomy: Safety results of a randomized trial. J Thorac Cardiovasc Surg 2019;158:895-907.

30. Asamura H, Okada M, Saji H, et al. Randomized Trial of 
Segmentectomy Compared to Lobectomy in Small-Sized Peripheral Non-Small Cell Lung Cancer (JCOG0802/ WJOG4607L). American Association for Thoracic Surgery 101st Annual Meeting 2021.

31. Liptay MJ, Basu S, Hoaglin MC, et al. Diffusion lung capacity for carbon monoxide (DLCO) is an independent prognostic factor for long-term survival after curative lung resection for cancer. J Surg Oncol 2009;100:703-7.

32. Ferguson MK, Little L, Rizzo L, et al. Diffusing capacity predicts morbidity and mortality after pulmonary

Cite this article as: Nakahama $\mathrm{H}$, Jaradeh $\mathrm{M}$, Abdelsattar ZM, Lubawski J, Vigneswaran WT. The impact of marginal lung function on outcomes in the era of minimally invasive thoracic surgery. J Thorac Dis 2021;13(12):6800-6809. doi: 10.21037/jtd$21-1382$ resection. J Thorac Cardiovasc Surg 1988;96:894-900.

33. Brunelli A, Refai MA, Salati M, et al. Carbon monoxide lung diffusion capacity improves risk stratification in patients without airflow limitation: evidence for systematic measurement before lung resection. Eur J Cardiothorac Surg 2006;29:567-70.

34. Ferguson MK, Dignam JJ, Siddique J, et al. Diffusing capacity predicts long-term survival after lung resection for cancer. Eur J Cardiothorac Surg 2012;41:e81-6. 